\title{
Microsatellite Marker for Cross-Species Amplification: Study Case for Indonesian Sundaland Python (Serpentes: Pythonidae)
}

\author{
Andri Maulidi ${ }^{1}$, Fatchiyah Fatchiyah ${ }^{1,2}$, Amir Hamidy $^{3}$, Nia Kurniawan ${ }^{1 *}$ \\ ${ }^{1}$ Departement of Biology, Faculty of Mathematics and Natural Science, University of Brawijaya, Malang, Indonesia \\ ${ }^{2}$ Research Center Smonagenes UB, Departement of Biology, Faculty of Mathematics and Natural Science, University of \\ Brawijaya, Malang, Indonesia \\ ${ }^{3}$ Laboratory of Herpetology, Museum Zoologicum Bogoriense, Research Center for Biology, Indonesian Institute of \\ Sciences-LIPI, Cibinong, Indonesia
}

\begin{abstract}
The python of Indonesian Sundaland has been traded for its distinct skin colour and patterns. The need for rapid method in cross-species amplification for Indonesian Sundaland python is useful to contribute in management of sustainability harvesting system. In this research, we screened 10 microsatellite primers which are previously used for Australian, New Guinean, Chinese and Burmese pythons and 7 potentially amplifiable primers for African and Asian reptiles. Python breitensteini showed a greater number of alleles (2-8 alleles) than Python bivittatus (1-3 alleles) and Python brongersmai (1-2 alleles). The observed and expected heterozygosity for all species were ranged from 0 to 1.00 and 0 to 0.79 , respectively. According to the high cross-species amplification rates, 15 out of 17 primers were useful in assessing the genetic diversity and conservation genetic of Indonesian Sundaland python. Among the 15 primers, MS3 generated the highest number of allele for $P$. breitensteini ( 8 alleles), $P$. bivittatus ( 3 alleles), and $P$. brongersmai ( 2 alleles). We proposed MS3 locus as a suitable marker for Indonesian Sundaland python.
\end{abstract}

Keywords: microsatellite, Python, Sundaland.

\section{INTRODUCTION}

Python is a nonvenomous snake and famous for its large body size. Among five species of python distributed in Indonesian Sundaland (Java, Borneo, and Sumatera), two of them are categorized into long-tailed python, namely reticulated python (Malayopython reticulatus) and Burmese python (Python bivittatus) and three of them are categorized into short-tailed pythons, namely Sumatran short-tailed Python (Python curtus), Brongersma's short-tailed Python (Python brongersmai), and Bornean short-tailed Python (Python breitensteini). Currently, the availability of python in the wild has gathered a great attention from Indonesian wildlife authorities due to massive threats of hunting in nature, deforestation and land conversion for agriculture $[1,2]$. Moreover, the demand for Indonesian Sundaland python for its skin color and patterns in the international market urged many conservation agencies to assist the management of wildlife trade. The information on the sustainability of harvesting system of Indonesian reticulated python was already described $[3,4]$. Harvesting of reticulated python in Indonesia officially only included one

\footnotetext{
* Correspondence address:

Nia Kurniawan

Email : wawan@ub.ac.id

Address: Dept. Biology, Faculty of Mathematics and Natural Science, University of Brawijaya, Veteran Malang, Malang 65145.
}

subspecies, $P$. reticulatus reticulatus which was widely distributed in Sumatra, Kalimantan, Java, and Sulawesi. The trade of two other subspecies, $P$. reticulatus saputrai (Selayar Island and Southwest Sulawesi) and $P$. reticulatus jampeanus (Tanahjampe Island), were banned according to Indonesian annual quota system. Therefore, management support regarding the harvesting system, including the use of molecular data to detect the origin of the specimens will be very beneficial for its implementation.

The use of microsatellite markers has been widely developed to detect illegal trade in many species such as broad-headed snakes, Hoplocephalus bungaroides [5], Cape parrot, Poicephalus robustus [6], and the identification of ivory species origin traded in African black market [7]. Previous studies also revealed the use of microsatellite primers on python, such as those for Australian and New Guinean pythons [8], invasive Burmese python (Python molurus bivittatus) [9] and Python bivittatus in China [10]. Meanwhile, little is known about Indonesian Sundaland pythons, including their genetic diversity. However, the development of microsatellite primers may cost considerable price and time consuming, in order that the use of cross-species amplification becomes an alternative way to find a suitable marker for closely related species determination. 


\section{MATERIALS AND METHODS}

A total of 13 specimens collected directly from the wild consisted of Python breitensteini ( $\mathrm{n}$ $=10)$ from Borneo, P. bivittatus $(n=2)$ from Java, and $P$. brongersmai $(\mathrm{n}=1)$ from Sumatera in 2016. Distinct color patterns of the three Sundaland pythons is showed in Figure 1. Animal ethics was approved by the Ethical Committee of Brawijaya University with the letter of Ethical
Clearance No: 68-KEP-UB. DNA was isolated from muscle tissue using Qiagen DNeasy kit following the manufacturer's instruction. Whole genomic DNA was analyzed qualitatively using $1 \%$ agarose gel and tested quantitatively using a spectrophotometer. We used 17 primers which have been designed for Morelia spilota [8] and Python bivittatus [9] and [11] (Supplementary 1).
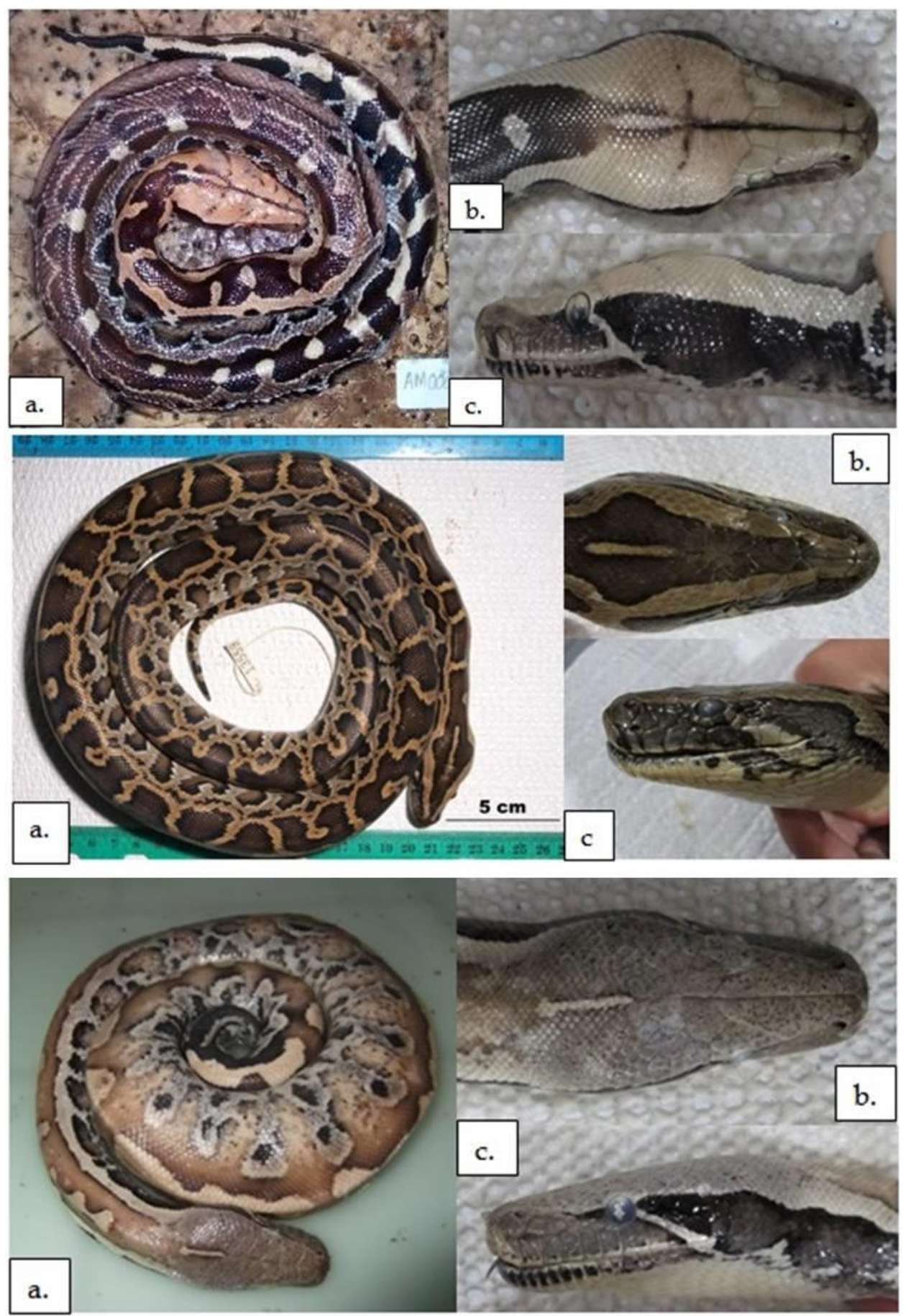

Figure 1. Distinct color patterns of the three Sundaland Pythons along the body (a), dorsal part of the head (b), and lateral part of the head (c) for Python breitensteini (up), Python bivittatus (middle), Python brongersmai (bottom). 
The PCR amplification was performed following the original authors for each primer, except that of [11] as followed: one cycle in $95^{\circ} \mathrm{C}$ for 5 minutes, 36 cycles in $94^{\circ} \mathrm{C}$ for 30 seconds, 55$62^{\circ} \mathrm{C}$ for 45 seconds, and $72^{\circ} \mathrm{C}$ for 40 seconds, and one cycle for final extension in $72^{\circ} \mathrm{C}$ for eight minutes. Annealing temperature for each primer and its amplification result can be seen in Supplementary 1. All PCR mixture was done in $40 \mu \mathrm{L}$ of reaction volume containing $20 \mu \mathrm{L}$ Go Taq $^{\circledR}$ green (Promega Co., USA), $0.8 \mu \mathrm{M}$ forward primer, $0.8 \mu \mathrm{M}$ reverse primer, $14.4 \mu \mathrm{L}$ nucleasefree water, and $4 \mu \mathrm{L}$ genomic DNA. The PCR products were visualized on $2 \%$ agarose gel with 100bp DNA Leader (Promega) as DNA marker. Calculation of the number of alleles $(\mathrm{Na})$, observed heterozygosity (Ho), and expected heterozygosity (He) were performed using GenAlEx 6.501 [12].

\section{RESULT AND DISCUSSION}

Majority of loci were amplified among three different species of python except that of MS5 in $P$. brongersmai and MS27 for $P$. bivittatus. Fifteen out of 17 primers produced various number of alleles which ranged from 1 to 3 for $P$. bivittatus, 1 to 2 for $P$. brongersmai, and 2 to 8 for $P$. breitensteini. However, we found fewer alleles than those observed for MS9 and MS16 loci [9]; and for MS5, MS13, and MS16 loci [10]. Nevertheless, this discrepancy might due to differences in sample sizes between the three studies. Higher number of samples is beneficial for obtaining more genetic variety within the population. Limited number of samples can be caused by short duration of sampling in each region and the number of alleles and heterozygosity can be increased by adding more samples and loci, as well as selecting certain loci with multiple alleles. However, the potential primer for cross-species amplification can be determined by the multiamplification ability. In this case, the cooccurrence of any alleles found in the three different species indicates the inferred potential primer.

Best markers were categorized by at least $50 \%$ of amplification success and those that were polymorphic with at least three alleles [13]. The observed heterozygosities ( $\mathrm{Ho})$ ranged from 0.00-0.60 for $P$. breitensteini, $0.00-1.00$ for $P$. bivittatus, and $0.00-1.00$ for $P$. brongersmai. The expected heterozygosity $(\mathrm{He})$ ranged from 0.20-0.79 for $P$. breitensteini, 0.00-0.63 for $P$. bivittatus, and 0.00-0.50 for P. brongersmai. Heterozygosity reflects allele variation within differ- ent loci which is an appropriate parameter for measuring genetic variation in a population [14]. The differences in genetic variability is likely due to differences in geographical and ecological conditions by which all three studied species were found in different islands. Python breitensteini is found only in Borneo, meanwhile $P$. brongersmai in Sumatera and $P$. bivittatus in Java Island [15].

The highest number of alleles was generated by MS3 for $P$. breitensteini (8 alleles), followed by MS1 (5 alleles), MS27 (5 alleles), MS13 (4 alleles), Pmb N14 (4 alleles) and KE961431.1 (4 alleles). However, MS3 was also amplified in $P$. bivittatus ( 3 alleles) and $P$. brongersmai ( 2 alleles) with higher number of alleles and samples than the other primers. The co-occurence of alleles found in this study and those observed in 13 python species [8] and in P. m. bivittatus of Florida [9] indicates the potensial use of these studied primers as forensic molecular markers. The success of cross-species amplification can occur due to the taxonomic proximity of the samples [16]. In addition, the high rate of amplification success in $P$. breitensteini provides the possibility for these markers, especially MS3 locus, in an untested species of Sumatran short-tailed python (Python curtus). Therefore, microsatellite loci described in our study would be useful for future identification of genetic diversity and population structure among Indonesian Sundaland python as well as providing effective information for wildlife management of python in Indonesia.

\section{CONCLUSION}

Cross-species amplification was successful in all three python species in Indonesia except in MS5 in P. brongersmai and MS27 for P. bivittatus. From these results it is found that MS3 is a marker with the highest number of alleles ( 8 alleles) for $P$. breitensteini.

\section{ACKNOWLEDGEMENT}

We would like to thank NK Research members, especially A.M. Kadafi and Agung Sih $\mathrm{K}$. , for helping the samples collection in Java and Sumatera and also to Wolly Candramila and Fitra Arya D.N. for constructive critique for improving this manuscript. This research was funded by LPDP Scholarship from the Ministry of Finance of Indonesia (PRJ-4409/LPDP.3/ 2016).

\section{REFERENCES}

[1] Myers, N., R.A. Mittermeier, C.G. Mittermeier, G.A.B. da Fonseca, J. Kent. 
2000. Biodiversity hotspots for conservation priorities. Nature. 403. 853-858.

[2] Sodhi, N.S., L.P. Koh, B.W. Brook, K.L.N. Peter. 2004. Southeast Asian biodiversity: an impending disaster. Trends Ecol. Evol. 19(12). 654-660.

[3] Shine, R., Ambariyanto, P.S. Harlow, Mumpuni. 1999. Reticulated pythons in Sumatra: biology, harvesting and sustainability. Biol. Conserv. 87(3). 349-357.

[4] Natusch, D.J.D., J.A. Lyons, Mumpuni, A. Riyanto, R. Shine. 2016. Jungle giants: assessing sustainable harvesting in a difficult-to-survey species (Python reticulatus). PLoS ONE. 11(7). e0158397.

[5] Frankham, G.J., M.C. Hinds, R.N. Johnson. 2015. Development of 16 forensically informative microsatellite loci to detect the illegal trade of broad headed snakes (Hoplocephalus bungaroides). Conserv. Genet. Resour. 7. 533.

[6] Pillay, K., D.A. Dawson, G.J. Horsburgh, M.R. Perrin, T. Burke, T.D. Taylor. 2010. Twentytwo polymorphic microsatellite loci aimed at detecting illegal trade in the Cape parrot, Poicephalus robustus (Psittacidae, AVES). Mol. Ecol. Resour. 10. 142-149.

[7] Wasser, S.K., A.M. Shedlock, K. Comstock, E.A. Ostrander, B. Mutayoba, S.M. Stephen. 2004. Assigning African elephant DNA to geographic region of origin: applications to the ivory trade. Proceedings of the National Academy of Sciences of the United States of America. 101. 14847-14852.

[8] Jordan, P.W., A.E. Goodman, S. Donnellan. 2002. Microsatellite primers for Australian and New Guinean pythons isolated with an efficient marker development method for related species. Mol. Ecol. Notes. 2. 78-82.

[9] Hunter, E.M., K.M. Hart. 2013. Rapid microsatellite marker development using next generation pyrosequencing to inform invasive Burmese Python-Python molurus bivittatus-management. Int. J. Mol. Sci. 14. 4793-4804.

[10] Duan, Y., Y. Wang, S. Bai, X. Tian, K. Rong, J. $\mathrm{Ma}, 2016$. Genetic diversity and population genetic structure of Python bivittatus in China. J. For. Res. 1-8.

[11] Shaney, K.J., R.H. Adams, N. Kurniawan, A. Hamidy, E.N. Smith, T.A. Castoe. 2016. A suite of potentially amplifiable microsatellite loci for reptiles of conservation concern from Africa and Asia. Conserv. Genet Resour. 8(3). 307-311.
[12] Peakall, R., O. Smouse. 2012. GenAlEx 6.5: Genetic analysis in Excel. Population genetic software for teaching and research - an update. J. Bioinf. 28(19). 2537-2539.

[13] Engelhardt, A., L. Muniz, D.P. Farajallah, A. Widdig. 2017. Highly polymorphic microsatellite markers for the assessment of male reproductive skew and genetic variation in critically endangered Crested Macaques (Macaca nigra). Int. J. Primatol. 38. 672-691.

[14] Frankham, R., J.D. Ballou, D.A. Briscoe. 2002. Introduction to conservation genetics. Cambridge University. Oxford. 78-83.

[15] Keogh, J.K., D.G. Barker, R. Shine. 2001. Heavily exploited but poorly know: systematics and biogeography of commercially harvested Pythons (Python curtus group) in Southeast Asia. Biol. J. Linnean Soc. 73. 113-129.

[16] Barbara, T., C. Palma-Silva, G.M. Paggi, F. Bered, M.F. Fay, C. Lexer. 2007. Crossspecies transfer of nuclear microsatellite markers: potential and limitations. Mol. Ecol. 16. 3759-3767. 
Suplementary 1. Amplification results for 17 microsatellite loci of three Sundaland Pythons

\begin{tabular}{|c|c|c|c|c|c|c|c|c|c|c|c|c|c|c|c|c|c|c|}
\hline \multirow{2}{*}{ Loci } & \multirow{2}{*}{ Primer Sequence $\left(5^{\prime}-3^{\prime}\right)$} & \multirow{2}{*}{$\begin{array}{c}\text { Repeat } \\
\text { Motif }\end{array}$} & \multirow{2}{*}{$\begin{array}{l}\mathrm{Ta} \\
\left({ }^{\circ} \mathrm{C}\right)\end{array}$} & \multicolumn{5}{|c|}{$\begin{array}{l}\text { P. breitensteini }(\mathrm{n}=10) \\
\text { (Least Concern) }\end{array}$} & \multicolumn{5}{|c|}{$\begin{array}{l}\text { P. bivittatus }(\mathrm{n}=2) \\
\text { (Vulnerable) }\end{array}$} & \multicolumn{5}{|c|}{$\begin{array}{l}\text { P. brongersmai }(n=1) \\
\text { (Least Concern) }\end{array}$} \\
\hline & & & & Success & $\begin{array}{l}\text { Range } \\
\text { (bp) }\end{array}$ & $\mathrm{Na}$ & Ho & $\mathrm{He}$ & Success & $\begin{array}{c}\text { Range } \\
\text { (bp) }\end{array}$ & $\mathrm{Na}$ & Ho & $\mathrm{He}$ & Success & $\begin{array}{c}\text { Range } \\
\text { (bp) }\end{array}$ & $\mathrm{Na}$ & Ho & $\mathrm{He}$ \\
\hline MS1* & $\begin{array}{l}\text { F:CACCATCCCCATCCTGAG } \\
\text { R:GAGAAGGATAATGCTGGATG }\end{array}$ & $(\text { AAAG })_{18}$ & 58 & $10 / 10$ & $480-550$ & 5 & 0.10 & 0.67 & $1 / 2$ & 600 & 1 & 0.00 & 0.00 & $1 / 1$ & 300 & 1 & 0.00 & 0.00 \\
\hline MS3* & $\begin{array}{l}\text { F: CCACAACCTAACCCAATC } \\
\text { R: ATCTGGAGCCTGAAGTCC }\end{array}$ & $(\mathrm{AAAG})_{15}$ & 54 & $10 / 10$ & $194-236$ & 8 & 0.60 & 0.79 & $2 / 2$ & $202-238$ & 3 & 0.50 & 0.63 & $1 / 1$ & 237 & 2 & 1.00 & 0.50 \\
\hline MS4* & $\begin{array}{l}\text { F: TATTTCATTTTCCCTATCTTCG } \\
\text { R: CAACTCAGTAGGGTGTCAG }\end{array}$ & $(\mathrm{AAAG})_{18}$ & 58 & $10 / 10$ & $312-359$ & 3 & 0,00 & 0.58 & $2 / 2$ & 359 & 1 & 0.00 & 0.00 & $1 / 1$ & 359 & 1 & 0.00 & 0.00 \\
\hline MS5* & $\begin{array}{l}\text { F: TAGGGTGTCAGTCATTGCTC } \\
\text { R: TGGCATCCAGCAGTCATAG }\end{array}$ & $(\mathrm{TTTC})_{17}$ & 59 & $9 / 10$ & $273-313$ & 3 & 0.00 & 0.57 & $2 / 2$ & 313 & 1 & 0.00 & 0.00 & $0 / 1$ & - & - & - & - \\
\hline MS9* & $\begin{array}{l}\text { F: CAGTGGGCTTGAGATTGAC } \\
\text { R: CATTCCTTAAAACACTCTCAC }\end{array}$ & $(A A A G)_{18}$ & 58 & $9 / 10$ & $198-218$ & 3 & 0.00 & 0.59 & $2 / 2$ & 198-207 & 2 & 0.00 & 0.50 & $1 / 1$ & 207 & 1 & 0.00 & 0.00 \\
\hline MS13* & $\begin{array}{l}\text { F: AACAGAGAAGCACAATCACC } \\
\text { R: TGGCTCTCACTTGATATATTAG }\end{array}$ & $(\mathrm{TTTC})_{16}$ & 59 & $10 / 10$ & $201-230$ & 4 & 0.00 & 0.70 & $2 / 2$ & 201 & 1 & 0.00 & 0.00 & $1 / 1$ & 201 & 1 & 0.00 & 0.00 \\
\hline MS16* & $\begin{array}{l}\text { F: GAGTTCTGGTCTTGCTTTCG } \\
\text { R: CAGGTACAACTTTCTCCAAC }\end{array}$ & $(\text { AAAG })_{12}$ & 59 & $8 / 10$ & $284-326$ & 3 & 0.00 & 0.59 & $1 / 2$ & 303 & 1 & 0.00 & 0.00 & $1 / 1$ & 284 & 1 & 0.00 & 0.00 \\
\hline MS27* & $\begin{array}{l}\text { F: TTACACAACAACCGCCATAG } \\
\text { R: CTTCTTATCCTGTTTACTCTG }\end{array}$ & $(\mathrm{TCTC})_{7}$ & 58 & $10 / 10$ & $233-279$ & 5 & 0.30 & 0.72 & $0 / 2$ & - & - & - & - & $1 / 1$ & 262 & 1 & 0.00 & 0.00 \\
\hline Pmb-K11** & $\begin{array}{l}\text { F: TTTGCTGCCCAGAGTTGTC } \\
\text { R: AGCAGTTTGACCTCATTCCAG }\end{array}$ & $(\text { AGAT })_{14}$ & 57 & $10 / 10$ & $226-235$ & 2 & 0.00 & 0.48 & $2 / 2$ & 226 & 1 & 0.00 & 0.00 & $1 / 1$ & 226 & 1 & 0.00 & 0.00 \\
\hline Pmb-N14** & $\begin{array}{l}\text { F: TTGGTAGTGGTGGTGGTGG } \\
\text { R: GGCTGGCTGCTACTGAAAC }\end{array}$ & $(\mathrm{GAT})_{13}$ & 62 & $10 / 10$ & $205-221$ & 4 & 0.00 & 0.66 & $2 / 2$ & 231 & 1 & 0.00 & 0.00 & $1 / 1$ & 221 & 1 & 0.00 & 0.00 \\
\hline KE966557.1*** & $\begin{array}{l}\text { F: GCCTCCTACTCAAAGGGTGG } \\
\text { R: CATGGGAGGCAAGGTAAAGG }\end{array}$ & $(\mathrm{AC})_{15}$ & 58 & $9 / 10$ & $348-378$ & 2 & 0.00 & 0.20 & $2 / 2$ & 378 & 1 & 0.00 & 0.00 & $1 / 1$ & 348 & 1 & 0.00 & 0.00 \\
\hline KE961431.1*** & $\begin{array}{l}\text { F: GAAGGGAGGCCCAAATATCC } \\
\text { R: GAGAGACCTGGTGCAAACCC }\end{array}$ & $(\mathrm{TC})_{10}$ & 58 & $9 / 10$ & $374-601$ & 4 & 0.11 & 0.50 & $2 / 2$ & 414 & 1 & 0.00 & 0.00 & $1 / 1$ & 414 & 1 & 0,00 & 0,00 \\
\hline KE955519.1*** & $\begin{array}{l}\text { F: AATTTTAGCTGCAGGCTGTGG } \\
\text { R: TCTGCTAGGGCAAAACTGGG }\end{array}$ & $(\mathrm{AC})_{90}$ & 59 & $10 / 10$ & $218-248$ & 3 & 0.00 & 0.64 & $2 / 2$ & 248 & 1 & 0.00 & 0.00 & $1 / 1$ & 248 & 1 & 0.00 & 0.00 \\
\hline KE961310.1*** & $\begin{array}{l}\text { F: AGGGTCAGGATTGAGGAGGG } \\
\text { R: TAGAGGCTGAAGGAGCCTGG }\end{array}$ & $(\mathrm{TCC})_{11}$ & 59 & $10 / 10$ & $305-336$ & 2 & 0.00 & 0.42 & $2 / 2$ & 336 & 1 & 0.00 & 0.00 & $1 / 1$ & 336 & 1 & 0.00 & 0.00 \\
\hline KE955203.1*** & $\begin{array}{l}\text { F: TGCATTTTCTCTTCCACAGGG } \\
\text { R: ATCTTCTGGGGAACCAACCC }\end{array}$ & $(\mathrm{TTC})_{35}$ & 57 & $7 / 10$ & $450-521$ & 2 & 0.00 & 0.24 & $2 / 2$ & 521 & 1 & 0.00 & 0.00 & $1 / 1$ & 450 & 1 & 0.00 & 0.00 \\
\hline KE959105.1*** & $\begin{array}{l}\text { F: CACTGTTTTGGGCCATCTCC } \\
\text { R:GGGTTTAGGATGTGTTCTGATTCC }\end{array}$ & $(\text { AATC })_{8}$ & 55 & $8 / 10$ & $514-527$ & 3 & 0,25 & 0.53 & $1 / 2$ & $514-523$ & 2 & 1.00 & 0.50 & $1 / 1$ & 526 & 1 & 0.00 & 0.00 \\
\hline KE961083.1*** & $\begin{array}{l}\text { F: AGTCCCAAACATCCAGAGGG } \\
\text { R: GGATCAAACCTGGACAAGCC }\end{array}$ & $(\mathrm{TTCC})_{13}$ & 59 & $10 / 10$ & $309-344$ & 3 & 0.00 & 0.54 & $2 / 2$ & 344 & 1 & 0.00 & 0.00 & $1 / 1$ & 344 & 1 & 0.00 & 0.00 \\
\hline
\end{tabular}

Success, indicated the number of successful amplification over total number of individuals tested; Na, total number of different alleles; Ne, total number of effective alleles; Ho, observed heterozygosity; He, expected heterozygosity. *Primers designed by [8]; **Primers designed by [9]; ${ }^{* * *}$ Primers designed by [11] 